\title{
Ankara Üniversitesi Sağlık Bilimleri Fakültesi Kütüphaneleri'nde Kataloglamada Uyumun Ölçülmesi
}

\author{
Measuring Cataloging Consistency in Health Sciences \\ Faculty Libraries at Ankara University
}

\section{Doğan ATILGAN* ve Özlem BAYRAM ${ }^{\star \star}$}

\begin{abstract}
Öz
Bu çalışmanın amacı, Ankara Üniversitesi sağlık bilimleri fakülteleri kütüphanelerinde kataloglama işlemlerindeki uyumun irdelenmesidir. MARC kayıtlarındaki farkılıkları belirlemek için dört fakülte kütüphanesinin çevrimiçi katalogları incelenmiş̧ir. Çalışmada, AAKK2'de izlenen temel giriş, başlık ve sorumluluk bildirimi, basım ve yayın, dağıtım (vb.) bildirimleri ile fiziksel niteleme, dizi ve ek giriş alanları karşılaştırılmıştır. Bulgular, incelenen erişim uçlarında belirli oranlarda tutarsızlıklar olduğunu ortaya koymaktadır. Bütün kütüphanelerdeki en yüksek oranda uyumsuzluk başlık ve sorumluluk bildirimi alanlarındadır.
\end{abstract}

Anahtar sözcükler: Kataloglama-Tutarlıık, Kataloglar-Karşılaştırmalı çalışmalar, Kataloglama-Üniversite kütüphaneleri, Kataloglama-Ankara Üniversitesi Kütüphaneleri.

\begin{abstract}
The purpose of this study was to examine the cataloging consistency between health sciences faculty libraries at Ankara University. Online catalogs at four faculty libraries are used to detect differencies in MARC records. Access points included AACR2, main entry, title statement and area of responsibility, edition statement, publication, distribution (etc.), physical description area, series area, and added entries are compared. Findings showed certain amount of inconsistency among the access points analysed. Highest numbers of inconsistencies among all libraries were found in the title and responsibility statement fields.
\end{abstract}

Keywords: Cataloguing-Consistency, Catalogues-Comparative studies, Cataloguing-University libraries, Cataloguing-Ankara University libraries,

\footnotetext{
* Doç.Dr. ; Ankara Üniversitesi DTCF Bilgi-Belge Yönetimi Bölümü Sıhhiye 06100 Ankara (atılgan@ankara.edu.tr).

** Yrd. Doç.Dr. ; Ankara Üniversitesi DTCF Bilgi-Belge Yönetimi Bölümü Sıhhiye 06100 Ankara (obayram@humanity.ankara.edu.tr).
} 


\section{Giriş}

Günümüzde çevrimiçi kataloglama işinin yaygın olarak yürütülmesi, kullanıcıların aradıkları bilgi kaynaklarına farklı bilgi merkezlerinden veya bu kaynak elektronik ortamda ise zaman ve mekân sınırı olmadan ulaşmalarını kolaylaştırmıştır. Bu nedenle bir kaynağa ilişkin tüm erişim uçlarının katalogda tam olarak bulunması ve bu erişim uçlarının, kaynağın aslında belirtildiği biçimiyle doğru olarak katalog kayıtlarına yansıtılması, o kütüphanedeki kaynakların tümüne eksiksiz erişim olanağını sağlar. Böylece kullanıcının, başvurduğu kütüphanede, aradığı kaynak bulunuyorsa 0 kaynağa erişememe olasılığı çok düşük bir düzeyde kalacaktır. Diğer yandan, hangi kütüphanede olursa olsun farklı otomasyon sistemlerinden girilen bibliyografik kayıtların biçim ve içerik yönünden uyumlu olması, bu kayıtların paylaşılmasına da izin verecektir. Bu nedenle geleneksel kataloglamada olduğu gibi çevrimiçi kataloglamada da standart kurallara uyulması, gerek kullanıcının bilgiye erişimi gerekse kütüphanedeki kataloglama işinin verimliliği açısından önemlidir.

Uluslararası Standart Bibliyografik Niteleme (International Standards Bibliographic Description-ISBD), bilgi kaynaklarına ilişkin niteleyici kataloglama kurallarında standart bir yapılanma öngörür. Bu standart yapı kataloglama işlemi yapılacak kaynağı niteleyen ögelerin hangi alanlarda ve hangi sırada verilmesi gerektiğini belirlemektedir. Bu özellik aynı zamanda MARC bibliyografik yapısının öngördüğü biçim ve içerik yapısı ISO 2907 ile AngloAmerikan Kataloglama Kuralları, 2. bs. (AAKK2) gibi standartlara göre düzenlenmiştir (Library of Congress, 2005). Kullanıcıların kütüphanelerdeki bilgi kaynaklarına doğru ve eksiksiz erişimlerini sağlamak yönünden bu standartlara uyulması büyük önem taşımaktadır. Bu amaçla öncelikle literatürde konunun ele alınışı araştırılarak kataloglamadaki farklı uygulamalara örnek oluşturan uyum değerlendirme çalışmaları incelenecektir. Bu bağlamda, çalışmanın ikinci bölümünde Ankara Üniversitesi'nin sağlık bilimleri fakültelerinin kütüphanelerinden seçilen kayıtların değerlendirilmesine yönelik bulgular tartışılmıştır.

\section{Kataloglamada Uyum Çalışmaları}

Literatürde, tutarlılık araştırmaları gerek dizinleme gerekse kataloglama etkinliklerinin ortak konusunu oluşturmaktadır. Her iki çalışma alanında da standartların ve mesleki eğitimin gerekliliği ve önemi tartışılmaz. Bu nedenle dizinleme ve kataloglama işlevlerinde tutarlılı̆ı araştıran çalışmalardan birlikte yararlanılması uygun görülmüştür. Bu konudaki çalışmaların çoğunluğu standart konu başlıkları, ya da kontrol dizinleri kullanılarak seçilen terim ve ifadelerin benzerlik oranlarının hesaplanmasına yönelik yöntem ve uygula- 
maları içermektedir (Arsenault, 2004; Chan, 1989; Iwe, 2001; Borko ve Tarr, 1974; Larson, 1992; Saarti, 2002; Tonta,1990). Çok önemli olmasına rağmen, son yıllarda farklı kütüphanelerde ya da farklı katalogcular arasında özellikle MARC alanlarındaki uyumun araştırılmasına yönelik çalışmaların azlığı şaşırtıcıdır. Bize göre bunun nedeni, bilgi merkezlerinde enformasyon teknolojisinin yaygınlaşması sonucunda kataloglama işlemlerinde, orijinal kataloglama yerine kayıt paylaşımı ve veri aktarımının tercih edilmesinden kaynaklanabilir. Böylece bu yolla gerçekleştirilen kataloglama işinin daha kolay ve düşük maliyetle yürütülebilmesinin yanı sıra, hata oranı da oldukça düşük düzeyde kalabilmektedir. Nitekim Vinh-The Lam (2005, s. 114) tarafından Amerika Birleşik Devletleri (ABD) ve Kanada'daki üniversite kütüphanelerine Library of Congress (LC) ve OCLC-WorldCat veri tabanlarından aktarılan katalog kayıtlarına ilişkin yapılan değerlendirmede tutarsızlık oranının \%2'den az olduğunu ortaya koymaktadır. Bu durumun "orijinal kataloglama"nın uygulandığı LC ve OCLC-WorldCat sistemlerinden kopyalama yöntemi ile alınan katalog kayıtlarında, hata oranının çok daha az olduğu saptanmıştır. Bir üniversite kütüphanesi ile Kongre Kütüphanesi'nde bulunan 5000 bibliyografik kayıt için belirlenen kontrollü terimlerin karşılaştıııldığı bir çalışmada, tutarlıık oranının oldukça yüksek olduğu ortaya çıkmıştır (Arsenault, 2004). Bununla beraber, ender olarak farklı dil ve alfabelerin kullanıldığı eserlerde bazı sorunlarla da karşılaşılabilmektedir. Örneğin, Yue Li (2004, ss. 17-31), OCLC veri tabanından aktarılan Çince kayıtların üzerinde yürüttüğü incelemede karşılaştığı tutarsızlıkları sekiz ayrı sınıfta değerlendirilmiştir. Tutarsızlıkların bir bölümü verilerin Çinceden Romen alfabesine dönüştürülmesi sırasında MARC alanlarında standart kuralların hatalı uygulanmasından kaynaklanmıştır.

Kataloglamada tutarlıık, kataloglama sürecinin verimliliğinin bir göstergesi olarak değerlendirilebilir. Bu anlamda tutarlılık, kataloglama ya da dizinleme işini yürütenler arasında ne ölçüde benzerlik ve uyum olduğunu ortaya koymaktadır (Stubbs, Mangiaterra ve Martinez, 1999). İki değişik dizinci tarafından aynı belgeye verilen dizinleme terimi ya da aynı kaynağa aynı dizinci tarafından değişik zamanlarda verilen terimleri karşılaştırma olarak niteleyebileceğimiz dizinlemede uyum derecesi, bir dokümana verilen bütün erişim terimlerinin, değişik zamanlarda verilen benzer terimlerle karşılaştırılması sonucu ortaya çıkmıştır (Hurwitz, 1969, s. 92).

Bibliyografik kayıtlar arasındaki uyuma önem verilmesiyle ilgili tartışmalar çok geriye gitmektedir. Waller (1970, s. 52), Kongre Kütüphanesi'nden katalog kayıtlarının sağlanmaya başladığı dönemlerde yazdığı makalesinde, bir araştırma kütüphanesindeki kataloglama sorunlarından söz ederken, orijinal kataloglamanın tercih edildiği durumlarda özellikle temel giriş ögesinin seçi- 
minde, Kongre Kütüphanesi kataloguna başvurulması ile kataloglama sürecinde birliğin sağlanabileceğini vurgulamıştır.

Gregor ve Mandel (1991, s. 46), yazdıkları bir makalede katalogcular arasında tutarııığın \%10-20 düzeyinde kaldığını ve bütünüyle bir tutarlılı̆ın aranmaması gerektiğini savunmuşlardır. Buna karşın, Mann (1997, ss. 3-45), böyle bir popülist yaklaşımın olumsuz sonuçlar doğuracağına dikkati çekerek, konunun önemini vurgulayan çalışmaları derleyen bir makale yayınlamıştır.

Bu çalışmaya benzer bir araştırmada, LC ve Dewey sınıflama sistemlerindeki sınıflama numaraları, konu başlıkları ve MARC kayıtları üzerinde toplam \%95 oranında bir uyumsuzluk belirlenmiş ve en büyük farklılı̆ın başlık ve sorumluluk bildirimi alanlarında ortaya çıktığı anlaşımıştır (Salaba, 1996, ss. 1-46).

Ülkemizde AAKK2'nin ilk defa uygulanmaya başlandığı 1985 yılından başlayarak beş yıllık bir süreci kapsayan bir çalışmada, Milli Kütüphane kayıtları kataloglama standartlarına uyum açısından değerlendirilmiştir. Türkiye Bibliyografyası'ndan seçilen yaklaşık 3800 eserin incelenmesi sonucunda Milli Kütüphane kayıtlarında bazı alanlarda \%70'in üzerinde uyumsuzluk olduğu ortaya konulmuştur (Atılgan, 1996).

Araştırmamızın kapsamı ile doğrudan ilgili bir başka çalışma, Malezya'daki üç üniversite kütüphanesinden seçilen birbirine benzer 410 kayıt üzerinde yürütülmüştür (Mansor, 2003). Çalışmada MARC yapısında verilen $1 \mathrm{xx}$ ve $7 \mathrm{xx}$ alanlarına girilen sorumluluk bilgilerinin söz konusu kayıtlar arasındaki uyumu analiz edilmiştir. Bu makalede tutarsızlığın izlendiği farklı uygulamalar üç grupta sınıflandırılmıştır: Birinci grupta alan, gösterge ve alt alan kodunun hatalı kullanılması ile oluşan MARC yapısına aykırı farklııklar; ikinci grupta kullanılması gerekli alan, alt alan ve göstergelere ilişkin bilgilere yer verilmemesi ile oluşan farklılıklar; üçüncü grupta ise yazım ve imla hataları yüzde değerleri ile yorumlanmıştır.

Zunde ve Dexter (1969, s. 321), çalışmasında tutarsızlığı etkileyen faktörleri üç sınıfta toplamaktadır: Mesleki eğitim ve deneyim, psikolojik koşullar ve motivasyon gibi nitelikler pragmatik faktörler; kaynağın konusu, kaynağa yönelik okuma, kontrollü dizine bağlı kalma, kullanılan yöntem ve araçlar semantik faktörler; çalışma alanında gürültü, iklim, aydınlık koşulları gibi unsurlar ise çevresel faktörler olarak değerlendirilmiştir. Farklı katalogcular arasında yapılan karşılaştırmalarda ortak politikaların geliştirilmesinden sonra rastlanan tutarsızlık oranında iyileşme gözlenmektedir (Stubbs, Mangiaterra ve Martinez, 1999). Bununla beraber, farklı kütüphane ve katalogcular için aynı araç, yöntem ve politikalar uygulansa bile belirli oranlarda bir tutarsızlığın kaçınılmaz olduğunu gösteren çalışmalar bulunmaktadır (Chan, 1989). 
Bu makalede, Ankara Üniversitesi'nin sağlık bilimleri fakülteleri kütüphaneleri arasında uygulanan kataloglama işlemlerinde ne ölçüde uyum olduğunu ortaya koymak amacıyla yürütülen güncel bir değerlendirme çalışması ile bu alanda verimliliği etkileyen unsurlara dikkat çekilmektedir.

\section{Ankara Üniversitesi Sağlık Bilimleri Fakültesi Kütüphanelerinde Kataloglamada Uyumun Ölçülmesi}

\section{Yöntem}

Ankara Üniversitesi'nde 15'i fakülte, 8'i yüksekokul ve 2'si araştırma merkezinde olmak üzere toplam 25 kütüphane bulunmaktadır. Bu kütüphanelerdeki toplam kayıt sayısı 440.824'dür. Bu çalışmanın alanı sadece sağlık bilimleri fakültelerinde bulunan 22,151 eserden benzer olan 982'sinin kaydı ile sınırlı tutulmuştur. Ancak, bu çalışma kütüphaneler arasında karşılaştırmaya dayandığı için iki ve/veya daha fazla kütüphanede ortak olarak bulunan eserlere ait 199 kayıt incelemeye alınmıştır. Kayıtların MARC verileri çevrimiçi katalogdan elde edilmiştir. Değerlendirmenin doğruluğu açısından seçilen her bir eserin kendisi incelenerek katalog kayıtları ile karşılaştırılmıştır. Bu kayıtların kütüphaneler arasındaki kataloglama kurallarına uyum dereceleri incelenmiştir. Değerlendirmeye alınan eserlerin incelenmesinde otorite olarak AKKK2'de belirtilen kurallar esas alınmıştır. Değerlendirmede bir başka ölçüt, bu fakülte kütüphanelerinin üniversitenin bünyesindeki diğer kütüphanelerin de kabul ettiği ortak kataloglama politikasını uyguluyor olmalarıdır. Bibliyografik kayıtların temel ve ek giriş ögesi ile birlikte ISBD standart alanlarında belirtilen kaynak türü özel ayrıntı alanı, notlar ve ISBN alanları dışındaki ögeler karşılaştırmaya dâhil edilmiştir. Bu ögeler, kütüphanelerin katalog kayıtları ile MARC standartları ve AAKK2'de öngörülen kurallar açısından değerlendirilmiştir. değerlendirme sonucu elde edilen tutarsızlıklara ilişkin veriler ayrı ayrı tablolar halinde verilmiştir. Tablolarda tek yazar, iki ve üç yazar, eser adı, tüzel kişi, kongrekonferans girişleri altında her farklılık ve/veya hata ayrı ayrı sayılmıştır. Alanlarda yer alan bilgi öbeklerindeki hatalar açıklamada verilmiş ancak yüzde değerleri verilirken aynı alandaki birden fazla hatalar o alan için tek hata sayılmıştır. Örneğin yayın bildirimi alanında bir eser için hem yayın yerinde, hem de yayınlayan adında hata yapılmışsa bunlar söz konusu alan için tek hata değeri olarak kabul edilmiş ve tablolarda yüzde oranları bu değer üzerinden verilmiştir. 


\section{Bulgular ve Değerlendirme}

Ankara Üniversitesine bağlı sağlık bilimleri konusunda eğitim veren dört fakülte (Diş Hekimliği, Eczacılık, Tıp ve Veterinerlik) kütüphanesinde yer alan eserlerden ortak olanların temel giriş ögesi, ISBD alanları ve ek giriş ögesi temel alınarak karşılaştırmalı değerlendirmesi yapılmıştır. Kataloglama kurallarının hatalı uygulanmasından kaynaklanan farklılıklar yüzde oranları ile tablolarda gösterilmiştir.

\section{Tablo 1: Temel Giriş Ögesi}

\begin{tabular}{|l|c|c|c|r|r|}
\hline Fakülteler & $\begin{array}{c}\text { Tek yazarlı } \\
\%\end{array}$ & $\begin{array}{c}\mathbf{2 - 3} \text { Yazarlı } \\
\%\end{array}$ & $\begin{array}{c}\text { Tüzel Kişi } \\
\%\end{array}$ & $\begin{array}{c}\text { Eser adı } \\
\%\end{array}$ & $\begin{array}{c}\text { Kongre- } \\
\text { Konf. \% }\end{array}$ \\
\hline Diş Hekimliği & 2,70 & 3,18 & 33,33 & - & - \\
\hline Eczacılık & 1,00 & 2,85 & 25,00 & - & 50,00 \\
\hline Tıp & 2,19 & 2,94 & - & 28,00 & 25,00 \\
\hline Veterinerlik & 5,88 & 3,22 & 50,00 & - & 20,00 \\
\hline
\end{tabular}

İncelemeye alınan kayıtlar temel giriş ögesi açısından değerlendirildiğinde yapılan hatalar fakülte kütüphanelerine göre farklılıklar göstermekle birlikte, kaynak türü olarak incelendiğinde her fakültede aynı tür eserlerde aynı hataların yapıldığı gözlenmiştir. Ancak Tıp Fakültesi Kütüphanesi, diğer kütüphanelerin hiç hata yapmadığı eser adı girişinde \%28'lik bir hata ile diğer üçünden ayrılmaktadır. Kaynak türlerine göre incelendiğinde, tek yazarlı ve iki-üç yazarlı eserlerde hata oranı \%10'un altında kalmıştır. Bu durumun nedeni, temel giriş ögesinin saptanmasının daha kolay olmasına bağlanabilir. Buna karşın, tüzel kişi, kongre-konferans gibi temel girişin belirlenmesinin daha karmaşık olduğu eserlerde hata oranının \%25'in üzerinde; hatta Eczacılık Fakültesi Kütüphanesi'nde kongre-konferans girişinde \%50 oranında hata yapılmış olması bilgiye erişimi engelleyen bir oran olarak değerlendirilebilir. Yine, tüzel kişi girişindeki \%33 oranındaki hataya karşılık eser adı ve kongre-konferans girişinde Diş Hekimliği Fakültesi Kütüphanesi'ndeki katalogcuların hiç hata yapmaması da olumlu olarak ele alınabilir. Veterinerlik Fakültesi Kütüphanesi'nde eser adı girişlerinde hiç hataya rastlanmamasına rağmen, diğer tüm girişlerde en yüksek hata oranına sahip olması bu alanda dikkat çeken diğer önemli bir bulgudur (Bkz. Tablo 1).

Başlıktan sonra ele alınan nitelemenin en önemli alanlarından olan eser adı ve sorumluluk bildirimi alanıdır. Bu alan AAKK2'nin öngördüğg̈ öz eser adı, paralel eser adı, başka eser adı ve sorumluluk bilgileri açısından değerlendirilmiştir. 
Tablo 2: Eser Adı ve Sorumluluk Bildirimi Alanı

\begin{tabular}{|l|c|c|c|c|r|}
\hline Fakülteler & $\begin{array}{c}\text { Tek yazarlı } \\
\%\end{array}$ & $\begin{array}{c}\mathbf{2 - 3} \text { Yazarlı } \\
\%\end{array}$ & $\begin{array}{c}\text { Tüzel Kişi } \\
\%\end{array}$ & $\begin{array}{c}\text { Eser adı } \\
\%\end{array}$ & $\begin{array}{r}\text { Kongre- } \\
\text { Konf. \% }\end{array}$ \\
\hline Diş Hekimliği & 8,10 & 36,36 & - & 42,85 & - \\
\hline Eczacılık & 16,83 & 80,00 & - & 44,82 & - \\
\hline Tıp & 28,57 & 70,58 & - & 56,00 & 25,00 \\
\hline Veterinerlik & 23,52 & 29,03 & 25,00 & 57,14 & - \\
\hline
\end{tabular}

Nitelemenin en önemli alanlarından biri olan eser adı ve sorumluluk bildirimi alanı fakülte kütüphaneleri tarafından en çok hata yapılan alanı oluşturmaktadır. Sorumluluk bildirimi alanında kongre-konferans girişinde Tıp Fakültesi Kütüphanesi'nde; tüzel kişi girişinde ise Veterinerlik Fakültesi Kütüphanesi'nde (alt eser adının alınmamasından kaynaklanan) \%25'şerlik hata oranları saptanmıştır. Tek yazarlı eserlerde en çok hata, Tıp ve Veterinerlik Fakülteleri kayıtlarında yapılmıştır. Örneğin bu kütüphanelerde bilginin ana kaynağında olan sorumluluk ibareleri (yazar, ortak yazarlar, editör gibi) ilgili alt alanda nitelemeye alınmamıştır.

Eser adı ve sorumluluk bildirimi alanında genel olarak en çok hataya 2 ve 3 yazarlı eserlerde rastlanmıştır. Bu gruptaki hataların ikinci veya üçüncü yazarların sorumluluk bildiriminde tekrar edilmemesi veya sorumlu olarak üstlendiği işlevin iç kapakta olmasına karşın nitelemeye alınmaması şeklinde olduğu saptanmıştır. İki ve üç yazarlı eserlerde, tek yazarlı eserlerden farklı olarak, en çok hatanın Eczacılık Fakültesi Kütüphanesi'nde yapıldığı; tek yazarlı eserlerde ise ikinci çok hata yapan Veterinerlik Fakültesi Kütüphanesi'nde ise 2-3 yazarlı eserlerde en az hatanın yapılmış olması ilginç bir sonuç oluşturmaktadır.

Hata oranının yüksek olduğu bir başka tür de temel girişin eser adına göre yapıldığı kaynaklardır. İki-üç yazarlı eserlerde en az hata oranına sahip Veterinerlik Fakültesi Kütüphanesi, bu türde en çok hata yapan birim durumundadır. Yapılan hatalar da genelde sorumluluk bildiriminde ilk yazarın tekrar edilmemesi şeklindedir (Bkz. Tablo 2). 
Tablo 3: Basım Bildirimi Alanı

\begin{tabular}{|l|c|l|l|l|c|}
\hline Fakülteler & $\begin{array}{c}\text { Tek yazarlı } \\
\%\end{array}$ & $\begin{array}{c}\mathbf{2 - 3} \text { Yazarlı } \\
\%\end{array}$ & $\begin{array}{c}\text { Tüzel Kişi } \\
\%\end{array}$ & $\begin{array}{c}\text { Eser adı } \\
\%\end{array}$ & $\begin{array}{c}\text { Kongre- } \\
\text { Konf. \% }\end{array}$ \\
\hline Diş Hekimliği & - & - & - & - & - \\
\hline Eczacılık & 4,95 & 5,71 & - & 6,89 & - \\
\hline Tıp & 1,03 & 5,88 & - & - & - \\
\hline Veterinerlik & - & 3,22 & - & 21,47 & - \\
\hline
\end{tabular}

Kataloglamada basım bildirimi, en az hata yapılan alanlardan birisi olmuştur. Karşılaşılan hatalar genelde 2-3 yazarlı eserlerde ve standart kısaltmaların kullanılmaması şeklindedir. Bu kısmın en ilginç bulgusu, seçilen eser türlerinin hepsi için diğer tüm birimlerde \%5-6'lık bir hata oranı söz konusu iken, Veterinerlik Fakültesi Kütüphanesi'nde eser adı girişinde bu sayı \%21'e çıkmaktadır. Bu oranın nedeni, yabancı dil eserlerde bu alana ilişkin bilgilerin de Türkçe oluşturulmasıdır (Bkz. Tablo 3). Çünkü AAKK2'ye göre basım bildirimi alanının eserin dilinde oluşturulması gerekir.

Tablo 4: Yayın Bildirimi Alanı

\begin{tabular}{|l|c|c|c|c|r|}
\hline Fakülteler & $\begin{array}{c}\text { Tek yazarlı } \\
\%\end{array}$ & $\begin{array}{c}\mathbf{2 - 3} \text { Yazarlı } \\
\%\end{array}$ & $\begin{array}{c}\text { Tüzel Kişi } \\
\%\end{array}$ & $\begin{array}{c}\text { Eser adı } \\
\%\end{array}$ & $\begin{array}{r}\text { Kongre- } \\
\text { Konf. \% }\end{array}$ \\
\hline Diş Hekimliği & 11,81 & 27,27 & - & - & - \\
\hline Eczacılık & 7,92 & 22,85 & - & 9,79 & - \\
\hline Tıp & 2,19 & 14,70 & - & 8,00 & - \\
\hline Veterinerlik & 11,76 & 21,42 & - & 6,45 & - \\
\hline
\end{tabular}

ISBD standartlarından dördüncüsünü yayın dağıtım ve benzeri alanı oluşturmaktadır. Bu alan yayın yeri, yayınlayan ve yayın tarihlerinin verilişindeki kural hataları ve yazım yanlışlıkları bakımından değerlendirilmiştir.

Yayın bildirimi alanındaki hataların genelde tek ve iki-üç yazarlı eserlerde toplandığı görülmüştür. Tüzel kişi ve kongre-konferans girişlerinde hiç hata saptanamazken, temel girişi eser adının oluşturduğu eserlerde Diş Hekimliği Fakültesi Kütüphanesi dışındakilerde \%10'un altında hataya rastlanmışıı (Bkz. Tablo 4). 
Yayın bildirimi alanında yapılan hataların çoğunluğunu ise, eserde yayıncı olduğu halde "yayınlayan yok" kısaltmasının kullanılması ve yayın yerindeki yazım hataları oluşturmaktadır. Tablo 4'de görüldüğü gibi, bu alanda elde edilen veriler ilginç bir sonuç sergilemektedir. Nitelemesinin daha basit olması beklenen tek ve iki-üç yazarlı eserler için tüm kütüphaneler hatalı giriş yaparken, daha karmaşık yapılarda hiç hata yapılmamış ya da az hata yapılmıştır. Tablodan elde edilen bir başka ilginç veri de, Diş Hekimliği Fakültesi Kütüphanesi'nin nitelemenin daha karmaşık olduğu düşünülen tüzel kişi, eser adı ve kongre-konferans girişlerinde hiç hata yapmazken, öncekilere göre nitelemenin daha basit olduğu yazar adı girişlerinde yüksek oranda hata yapmış olmasıdır.

\section{Tablo 5: Fiziksel Niteleme Alanı}

\begin{tabular}{|l|c|c|c|r|r|}
\hline Fakülteler & $\begin{array}{c}\text { Tek yazarlı } \\
\%\end{array}$ & $\begin{array}{c}\mathbf{2 - 3} \text { Yazarlı } \\
\%\end{array}$ & $\begin{array}{c}\text { Tüzel Kişi } \\
\%\end{array}$ & $\begin{array}{c}\text { Eser adı } \\
\%\end{array}$ & $\begin{array}{r}\text { Kongre- } \\
\text { Konf. } \%\end{array}$ \\
\hline Diş Hekimliği & 2,70 & 2,70 & 5,20 & 7,14 & 6,10 \\
\hline Eczacılık & 3,96 & 14,28 & - & 6,89 & 2,80 \\
\hline Tıp & 2,19 & 2,94 & 3,50 & 4,00 & - \\
\hline Veterinerlik & 23,52 & 19,35 & 25,00 & 71,42 & 18,60 \\
\hline
\end{tabular}

Bir erişim ucunu oluşturmayan ancak eserlerin fiziksel özellikleri hakkında bilgi edinmemizi sağlayan bir diğer alan da fiziksel niteleme alanıdır.

Hiç hata olmaması beklenen fiziksel niteleme alanında, genelde tüm kütüphanelerin her tür eser girişinde hata yapıldığı saptanmıştır. Mevcut hataların genel olarak resimleme ögelerinin alınmaması ve/veya standart kısaltmaların kullanılmaması şeklinde olduğu tespit edilmiştir (Bkz. Tablo 5).

$\mathrm{Bu}$ alanda dikkat çeken en önemli nokta, Veterinerlik Fakültesi Kütüphanesi'nin seçilen kayıtların tümünde gerekli öğeleri vermeyerek diğer kütüphanelerle uyumsuzluk göstermesidir. Bu kütüphanede sadece sayfa sayısının verilip diğer öğelerin alınmaması uyumsuzluğun başlıca nedeni olmuştur.

Böyle bir sonucun, en basit ve bilgiye erişimi engellemeyen niteleme amaçlı alana gerekli dikkatin gösterilmemesinden kaynaklandığı düşünülmektedir. Nedeni ne olursa olsun, standart bir uygulamayı gerektiren kurallar topluluğundan oluşan kataloglamanın bir alanında, bir kütüphanenin kayıtlarında gözlenen \%70'e varan eksik bilgi düşündürücü bir sonuçtur. 
Tablo 6: Dizi Bildirimi Alanı

\begin{tabular}{|l|c|c|c|c|r|}
\hline Fakülteler & $\begin{array}{c}\text { Tek yazarlı } \\
\%\end{array}$ & $\begin{array}{c}\mathbf{2 - 3} \text { Yazarlı } \\
\%\end{array}$ & $\begin{array}{c}\text { Tüzel Kişi } \\
\%\end{array}$ & $\begin{array}{c}\text { Eser adı } \\
\%\end{array}$ & $\begin{array}{r}\text { Kongre- } \\
\text { Konf. } \%\end{array}$ \\
\hline Diş Hekimliği & 16,21 & 2,70 & - & 14,28 & 33,33 \\
\hline Eczacılık & 8,91 & 8,57 & 25,00 & 3,44 & 12,55 \\
\hline Tıp & 4,39 & 5,88 & 30,00 & 4,00 & - \\
\hline Veterinerlik & 13,60 & 9,67 & 75,00 & 14,28 & 40,00 \\
\hline
\end{tabular}

Dizi bildirim alanında, hata oranının yüksek olduğu ve tüm eser türlerine dağıldığı gözlenmiştir. Bu alanda yazım ve kural hatası yanında MARC alt alan kodunun verilişinde de uyumsuzluk saptanmıştır.

Veterinerlik ve Diş Hekimliği Fakülteleri Kütüphanelerinde genel olarak alt dizi adlarının alınmaması ve dizi numarasından önce verilmesi gereken, MARC alt alan kodu olan "\$v"nin verilmemesi şeklinde hatalar saptanmıştır. $\mathrm{Bu}$ alanda elde edilen bir başka sonuç, basım ve yayın bildiriminde hiç hatanın gözlenmediği tüzel kişi ve kongre-konferans girişlerinde, kütüphanelerin yüksek oranda hata yapmış olmalarıdır. Veterinerlik Fakültesi Kütüphanesi'nde önceki diğer alanlarda olduğu gibi, dizi bildirim alanında da incelenen tüm örneklerde yüksek oranda hataya rastlanmıştır (Bkz. Tablo 6).

Tablo 7: Ek Giriş Ögesi

\begin{tabular}{|l|c|c|c|c|r|}
\hline Fakülteler & $\begin{array}{c}\text { Tek yazarlı } \\
\%\end{array}$ & $\begin{array}{c}\mathbf{2 - 3} \text { Yazarlı } \\
\%\end{array}$ & $\begin{array}{c}\text { Tüzel Kişi } \\
\%\end{array}$ & $\begin{array}{c}\text { Eser adı } \\
\%\end{array}$ & $\begin{array}{r}\text { Kongre- } \\
\text { Konf. \% }\end{array}$ \\
\hline Diş Hekimliği & 2,70 & 6,55 & - & 5,12 & - \\
\hline Eczacılık & 1,00 & 8,57 & - & 13,79 & - \\
\hline Tıp & - & 8,82 & - & 4,00 & - \\
\hline Veterinerlik & 2,94 & 7,45 & - & 21,42 & - \\
\hline
\end{tabular}

ISBD alanları içinde yer almayan, ancak bilgiye erişim için önemli öğelerden birisi de ek girişlerdir. Ankara Üniversitesi Kütüphaneleri'nde konu başlıkları yaygın ve standart olarak kullanılmadığı için değerlendirmeye alınmamıştır.

MARC standardında 700 ön eki (tag) ile tanımlanan ek giriş öğeleri kataloglamada uyum açısından değerlendirilmiştir. Bu girişlerin değerlendirilmesinde tüzel kişi ve kongre-konferans girişlerinde hata yapılmadığı belirlen- 
miştir. Bu alanlarda genelde emeği geçen bilgilerinin yaygınlıkla yer almadığı şeklinde yorumlanabilir. Bu durumu doğrulayan bir gösterge ise, ek girişin zorunlu olduğu temel girişin eser adına göre yapıldığı ve iki-üç yazarlı eserlerde hata oranının yüksek olmasıdır.

Bu alanda yapılan hatalar, ek giriş ögesinin oluşturulmaması, bilginin ana kaynağındaki sorumluluk ibaresinin veriliş biçimine (yazanlar, Türkçeye çeviren vb.) dikkat edilmemesi ve ek girişin yapıldığı adlara eserdeki sorumluluk ibaresinin eklenmesi (editör, çeviren vb.) şeklindedir (Bkz. Tablo 7).

Tablo 8: Genel Değerlendirme

\begin{tabular}{|l|c|c|c|c|c|c|r|}
\hline Fakülteler & $\begin{array}{c}\text { Başık } \\
\%\end{array}$ & $\begin{array}{c}\text { Eser adı / } \\
\text { Sorumluluk }\end{array}$ & Basım & Yayın & $\begin{array}{l}\text { Fiziksel } \\
\text { Niteleme }\end{array}$ & Dizi & Ek giriş̧ \\
\hline Diş Hekimliği & 5,88 & 19,64 & - & 10,29 & 4,41 & 11,76 & 1,47 \\
\hline Eczacılık & 3,46 & 33,52 & 5,20 & 11,56 & 6,35 & 5,20 & 4,62 \\
\hline Tıp & 7,05 & 41,66 & 1,92 & 5,12 & 3,20 & 4,48 & 2,56 \\
\hline Veterinerlik & 5,88 & 35,58 & 2,35 & 8,23 & 30,58 & 17,64 & 4,70 \\
\hline
\end{tabular}

Ankara Üniversitesi sağlık bilimleri fakülteleri kütüphanelerin katalog kayıtlarının temel giriş ögesi, ISBD alanları ve ek giriş ögesi açısından incelenmesi sonucunda, Diş Hekimliği Fakültesi Kütüphanesi'nin basım bildirimini doğru verdiği; buna karşılık tüm birimlerin tüm alanlarda hata yaptığı saptanmıştır (Bkz. Tablo 8).

Bu hataların yaklaşık \%20 ve üzerindeki değerlerle eser adı ve sorumluluk bildirimi alanında olduğu saptanmıştır. Başlık ve eser adı gibi iki önemli erişim ucunun yer aldığı bölümlerde en çok, diğer alanlarda da en az hata Tıp Fakültesi Kütüphanesi tarafından yapılmıştır. Fiziksel niteleme, dizi bildirimi ve ek giriş ögelerinin verilişinde, en yüksek hata oranına sahip Veterinerlik Fakültesi Kütüphanesi, başlık ve eser adı sorumluluk alanında da ikinci sırada yer almıştır.

Bulgular genel olarak değerlendirildiğinde, fakülte kütüphanelerinin katalog kayıtlarında, Ankara Üniversitesi Kütüphanesi'nin kataloglama politikasına temel oluşturan MARC standardı ve AAKK2'nin öngördüğü kuralların uygulanmasında sorunlar olduğu ortaya çıkmaktadır. Uluslararası kataloglama standardı ve kurallarına uyumsuzluktan kaynaklanan bu hatalar bilginin ana kaynağındaki biçime bağlı kalmama, bilgilerin eksik alınması (başka eser adı, ikinci dereceden sorumlular alt dizi gibi) ve noktalama işaretlerinin yanlış kullanılması konusunda yoğunlaşmıştır. 


\section{Sonuç}

Bir kurallar ve standartlar mesleği olarak kütüphaneciliğin en önemli standartlarından olan kataloglama işlemlerinde, Ankara Üniversitesi'nin sağlık bilimleri ile ilgili dört fakülte kütüphanesinde kataloglama kurallarının uygulanışı arasındaki uyumun araştııılığı bu çalışmada ilginç sonuçlar elde edilmiştir. Ankara Üniversitesi Kütüphaneleri'nden seçilen bibliyografik kayıtlar üzerinde yürütülen çalışmada, uyumsuzluk oranı dört kütüphane için farklı eser girişlerine göre ayrı ayrı belirlenmiştir. Buna göre başıkta ve eser adı/sorumluluk alanında en fazla hata oranı Tıp Fakültesi Kütüphanesi kayıtlarında gözlenirken; fiziksel niteleme, dizi bildirimi ve ek girişlerde ise en fazla hata oranı Veterinerlik Fakültesi Kütüphanesi kayıtlarında ortaya çıkmıştır. Diş Hekimliği Fakültesi Kütüphanesi kayıtlarında basım bildirimine ilişkin hiçbir hata gözlenmezken, aynı kayıtlarda eser adı girişi ve ek girişlerde en az hata oranı tespit edilmiştir. Eczacılık Fakültesi Kütüphanesi'nde en az hata, başlık alanında yapılmıştır. Bu durumda farklı alan ve farklı eser girişleri için söz konusu olsa bile seçilen tüm kütüphane kayıtlarında belirli oranlarda uyumsuzluk olduğu ortaya çıkmaktadır. Bütün birimlerin en yüksek oranda uyumsuzluk gösterdiği alan, eser adı ve sorumluluk bildirimi alanıdır.

Bilgi ve deneyim gerektiren ve bilgiye erişim için önemli niteleme alanlarında büyük oranda hata yapılması ve kataloglamada uyumun bulunmaması ilgili kütüphanelerde geçmiş yıllarda kütüphanecilik eğitimi almış kimsenin bulunmamasına bağlanabilir. Kütüphanecilik bilgisi ve deneyimi gerektirmeyen fiziksel niteleme alanındaki hatalar ise, gerekli özen ve dikkatin gösterilmemesinden kaynaklanmış olabilir. Ancak, uzun süredir kütüphanecilik eğitimi almış görevlilerin çalıştığı tespit edilen Veterinerlik Fakültesi Kütüphanesi'nde tüm alanlarda yüksek oranda hata yapılması ile yine son yıllara kadar kütüphanecilik eğitimi almış bir görevlinin bulunduğu Eczacılık Fakültesi Kütüphanesi'nde eser adı ve sorumluluk bildirimi alanında en yüksek ikinci sırada hatanın yapılmasının ve kütüphaneler arasında bazı alanlarda \%50'ye varan uyumsuzluğun gerekçelerini bilimsel bir tabana dayandırmak zordur. Diğer yandan, söz konusu kütüphanelerde aynı otomasyon programı kullanılmasına rağmen farklı katalogcular arasında belirli oranlarda uyumsuzluk olduğu ortaya çıkmaktadır. Ankara Üniversitesi Kütüphaneleri için ortak kataloglama ilke ve politikalarının oluşturularak 1999 yılında basılı metin halinde kütüphanecilerin dikkatine sunulduğu bilinmektedir. Literatürde yaygın olarak ifade edildiği gibi, gerek konu başlıkları ya da kontrollü dizin kullanımında, gerekse AAKK2 ve MARC standartlarının kullanımında ortak politika ve yöntemlerin uygulanması farklı katalogcular arasında tutarsızlık sorununu ortadan kaldırmamaktadır. Bu durumun bir başka örneği de eldeki çalışmada ortaya konmuştur. 
Bilimsel bir yaklaşımla belirlenen sorunun çözümü için, sadece söz konusu kütüphanelerde değil, tüm birimlerde ortak bir hizmet içi eğitim programı düzenlenmesi ilk adımda yararlı olabilir. Özellikle, yaygın olarak uyumsuzluğun gözlendiği eser adı ve sorumluluk bildirimi, yayın bildirimi ve fiziksel niteleme alanları için kütüphanecilerin daha dikkatli olmaları gerekmektedir. Kataloglamada standart kurallara uyulması ile bilgi erişimi arasında organik bir bağ olduğu düşüncesine tüm kütüphanecilerin ciddiyetle yaklaşmaları sağlanarak anılan sorunların en az düzeye ineceği söylenebilir.

\section{Kaynakça}

Arsenault, C. (2004, 3-5 Haziran). Measuring and comparing aggregation inconsistency for Chinese titles in two library catalogues. CAIS/ACSI 2004 Access to Information: Technologies, Skills, and Socio-Political Context'de sunulan bildiri. 20 Nisan 2006 tarihinde http:// www.cais-acsi.ca/proceedings/2004/arsenault_2004.pdf adresinden erişildi.

Atılgan, D. (1996). Kataloglamada tutarlıık açısından Türkiye Bibliyografyası (1985 - 1990). Ankara: Milli Kütüphane Başkanlığı.

Borko, H. ve Tarr, D. (1974). Factors influencing inter-indexer consistency. P. Zunde (Ed.). Information utilities: Proceedings of the 37th ASIS Annual Meeting Atlanta, Georgia, October 13-17 1974 içinde (v. 11, ss. 50-55). Washington, DC: ASIS.

Chan, L.M. (1989). Inter-indexer consistency in subject cataloging. Information Technology and Libraries, 8 (4), 349-358.

Gregor, D. ve Mandel, C. (1991). Cataloging must change. Library Journal, 116 (6), $42-47$.

Hurwitz, F.I. (1969). A study of indexer consistency. American Documentation, 20 (1), 92-94.

Iwe, J.I. (2001). Linguistics and information processing: Provision of syntactic and semantic consistency in the language of Library of Congress Subject Headings (LCSH) pertaining to literature and librarianship: A comparative analysis. Cataloging \& Classification Quarterly, 32 (2), 107-126.

Lam, V.T. (2005). Quality control issues in outsourcing cataloging in United States and Canadian Academic Libraries. Cataloging \& Classification Quarterly, 40 (1), 101-122.

Larson, R.R. (1992). Experiments in automatic Library of Congress classification. Journal of the American Society for Information Science, 43 (2), 130-148. 
Li, Y. (2004). Consistency versus inconsistency: Issues in Chinese cataloging in OCLC. Cataloging \& Classification Quarterly, 38 (2), 17-31.

Library of Congress. (2005). MARC standards. 20 Nisan 2006 tarihinde http://www.loc.gov/marc/ adresinden erişildi.

Mansor, Y. (2003). Bibliographic exchange in Malaysia: Variations in name headings. Library Review , 52 (1), 38-42.

Mann, T. (1997). "Cataloging must change!" and indexer consistency studies: Misreading the evidence at our peril. Cataloging \& Classification Quarterly, 23 (3/4), 3-45.

Saarti, J. (2002). Consistency of subject indexing of novels by public library professionals and patrons. Journal of Documentation, 58 (1), 49-65.

Salaba, A. (1996). Inter-indexer consistency in bibliographic record access points between OCLC and RLIN. Master's Research Paper (MA). Kent State University, Ohio. 20 Nisan 2006 tarihinde http://eric.ed.gov/ ERICDocs/data/ericdocs2/ content_storage_01/0000000b/80/23/55/18.pdf adresinden erişildi.

Stubbs, E.A., Mangiaterra, N.E. ve Martinez, A.M. (1999). Internal quality audit of indexing: A new application of interindexer consistency. Cataloging \& Classification Quarterly, 28 (4), 53-69.

Tonta, Y. (1990). Kataloglamada tutarlılık üzerine bir araştırma. Prof. Dr. Osman Ersoy'a Armağan içinde (ss. 135-143). Ankara: Türk Kütüphaneciler Derneği.

Waller, S.B. (1970). Thoughts on cataloging and classification in a small medical library. Bulletin of Medical Library Association, 58 (1), 51-57.

Zunde, P. ve Dexter, M. (1969). Factors effecting indexing performance. Proceedings of the American Society for Information Science: 32nd Annual Meeting, San Fransico, California, October 1-4, 1969 içinde (ss. 313-322). Westport, Conn.: Greenwood Publishing Co. 